\title{
Neurological Deficit or Dysfunction
}

National Cancer Institute

\section{Source}

National Cancer Institute. Neurological Deficit or Dysfunction. NCI Thesaurus. Code C50672.

A finding of pathologic function within the central or peripheral nervous system, secondary to developmental abnormalities, infections, neurologic damage, or tumors. 